\title{
REVIEW
}

\section{Information from cochlear potentials and genetic mutations helps localize the lesion site in auditory neuropathy}

\author{
Rosamaria Santarelli*
}

\begin{abstract}
Auditory neuropathy (AN) is a disorder characterized by disruption of auditory nerve activity resulting from lesions involving the auditory nerve (postsynaptic AN), inner hair cells and/or the synapses with auditory nerve terminals (presynaptic AN). Affected subjects show impairment of speech perception beyond that expected for the hearing loss, abnormality of auditory brainstem potentials and preserved outer hair-cell activities. Furthermore, AN can be identified either as an isolated disorder or as an associated disorder with multisystem involvement including peripheral and optic neuropathies (non-isolated AN). Mutations in several nuclear and mitochondrial genes have been identified as underlying these forms of AN. Recently, new genes have been identified as involved in both isolated (DIAPH3, OTOF) and non-isolated AN (OPA1). Moreover, abnormal cochlear potentials have been recorded from patients with specific gene mutations by using acoustic stimuli or electrical stimulation through cochlear implant. In this review, different types of genetically based auditory neuropathies are discussed and the proposed molecular mechanisms underlying AN are reviewed.
\end{abstract}

\section{Auditory neuropathy: a rare disorder?}

Auditory neuropathy (AN) is a hearing disorder characterized by disruption of temporal coding of acoustic signals in auditory nerve fibers resulting in impairment of auditory perceptions that rely on temporal cues. Abnormal discharge of auditory fibers results from lesions involving the nerve fibers themselves (postsynaptic AN), the inner hair cells (IHCs) or their

*Correspondence: rosamaria.santarelli@unipd.it

Department of Medical and Surgical Specialities, Service of Audiology and

Phoniatrics, University of Padua, Via Giustiniani 2, I-35128 Padua, Italy synapses with auditory nerve terminals (presynaptic AN) [1]. The disruption of auditory nerve discharge underlies both the absence of or profound alterations in auditory brainstem responses and the severe impairment of speech perception. In contrast, cochlear receptor outer hair cell $(\mathrm{OHC})$ activities are preserved. This is indicated by the detection of otoacoustic emissions (OAEs), which are sounds produced by the active contraction of OHCs [2], and by recording of cochlear microphonics, which result from the vector sum of the extracellular components of the receptor potentials arising in $\mathrm{OHCs}$ [3].

Auditory neuropathy can be congenital or acquired. Congenital AN affects the development of language, an ability that is strictly related to the existence of a sensitive period declining with age [4]. In this period, the development of language skills is strictly dependent on cortical plasticity and requires an efficient auditory input [4]. When the onset of AN is delayed to childhood or adult life (acquired AN), abnormalities of auditory input lead to severe impairment of speech perception and progressive deterioration of acquired language skills [1].

Both the congenital and acquired forms of AN can be due to genetic disorders or can have a wide range of other etiologies (for example, infections, toxic metabolite damage or immunological damage) [1,5]. Nevertheless, no etiologic factors can be identified in approximately half of the patients [1]. All forms of the disorder may be present in isolation (isolated AN) or be associated with multisystem involvement (non-isolated AN).

Auditory neuropathy occurs in all age groups [1] and its reported prevalence varies from $1 \%$ to $10 \%$ [6]. This high variability may reflect the inclusion in some studies of diseases in which the AN disorder is transient, such as Guillain-Barré syndrome [5]. Moreover, in neonates admitted to neonatal intensive care units showing absent auditory brainstem responses and the presence of OAEs at newborn hearing screening [7], the brainstem response abnormalities may reflect delayed maturation of both brainstem and auditory nerve generators. On the other hand, some hearing disorders underlying AN might not 
have been included in prevalence estimates as the identification of the AN picture in cooperative patients may require several tests to be performed in addition to hearing-threshold evaluation, and these are not invariably included in routine diagnosis. Refined diagnostics together with progress in genetic research will provide a more accurate calculation of the prevalence of AN disorders and, among them, of forms with a genetic etiology.

Clinical criteria for diagnosis include impairment of speech perception beyond that expected for hearing loss, the absence or marked abnormality of auditory brainstem responses and preserved $\mathrm{OHC}$ activities (OAEs and/or cochlear microphonics). Nevertheless, some patients with AN may have normal hearing thresholds and an impairment of speech perception that is only apparent in the presence of noise [1]. In these subjects the evaluation of speech perception in noise and psychoacoustical testing (gap detection, frequency discrimination) [8] are mandatory. Cochlear implantation constitutes the only rehabilitative tool able to restore speech perception in patients affected by presynaptic AN [9] or in postsynaptic AN localized to the distal portions of auditory nerve fibers $[10,11]$.

In the past decade, the identification of several genes involved in the pathogenesis of both presynaptic and postsynaptic AN has greatly contributed to the diagnosis and better understanding of mechanisms underlying this disorder. This review will provide a description of all the genes so far discovered to be involved in the pathology of auditory neuropathy, including those most recently identified such as DIAPH3, OTOF and OPA1. The effects of the abnormal function of gene products at the cellular level, the histopathologic findings in animal models, and electrophysiological recordings obtained from patients carrying specific gene mutations will be reviewed. Moreover, possible mechanisms underlying the alteration of auditory nerve discharge will be discussed for mutations of individual genes.

\section{The genetic disorders underlying auditory neuropathy}

All the genes and loci implicated in the pathogenesis of AN so far are listed in Table 1 under the categories isolated AN or non-isolated AN.

\section{Genes involved in isolated AN}

Specific gene mutations underlying isolated AN constitute a unique opportunity to relate AN to specific alterations in single-cell function and metabolism. Of these, mutations in the OTOF gene with a recessive pattern of inheritance are the best known. It has been estimated that these mutations are responsible for at least 3\% of cases of prelingual non-syndromic hearing impairment in the Spanish population [12,13]. OTOF encodes otoferlin, a transmembrane protein belonging to the ferlin protein family, which contains several repeating C2 domains involved in calcium binding [14]. Otoferlin plays a crucial role in vesicle release at the synapse between IHCs and auditory nerve fibers by interacting with syntaxin1 and SNAP25 [15], and it has recently been implicated in vesicle replenishment at the presynaptic membrane [16]. To date, more than 40 pathogenic mutations of the OTOF gene have been identified [13], all resulting in a very homogeneous phenotype of prelingual, profound hearing loss with an absence of, or marked threshold elevation of, auditory brainstem responses. More than $50 \%$ of subjects carrying biallelic OTOF mutations also show preserved function of $\mathrm{OHCs}$ as indicated by OAE recording [13]. The absence of OAEs in half the patients with OTOF mutations does not rule out AN, as the disappearance of OAEs over time has been reported in several AN disorders as possibly reflecting delayed involvement of $\mathrm{OHCs}$ in the pathological process [1].

Missense mutations in the PJVK gene associated with AN have been identified with a recessive pattern of inheritance in four Iranian families whose affected members showed congenital profound hearing loss and presence of OAEs [17]. PJVK encodes pejvakin, a 352-residue protein belonging to the gasdermin protein family, localized in the hair cells, supporting cells and spiral ganglion neurons, whose function remains unknown [17]. Nevertheless, the association of $\mathrm{AN}$ and PJVK gene mutations has been questioned [18], as no OAEs have been obtained from families carrying the same mutations as those reported in [17], while truncating mutations in the PJVK gene may be associated with progressive hearing loss without OAE detection [19].

An autosomal dominant auditory neuropathy, AUNA1, has been identified in an American family of European descent whose affected members showed moderate hearing loss beginning in the second decade of life and progressing to severe deafness in the fifth decade [11]. Due to improvement of auditory functions and restoration of electrically evoked brainstem potentials after cochlear implantation, abnormal function of the distal portion of auditory nerve fibers was hypothesized. Recently, a point mutation (c. $-172 \mathrm{G}>\mathrm{A}$ ) has been identified in a highly conserved region (5' UTR) of the DIAPH3 gene of the affected members. The DIAPH3 gene is one of the three human orthologs of Drosophila Diaphanous and encodes a protein belonging to the formin protein family [20]. This is an actin-nucleation factor implicated in the maintenance of cell and stereocilium shape, vesicle trafficking, and other cell activities through the regulation of actin polymerization [21]. DIAPH3 mutation leads to an overexpression of DIAPH3 protein [20], which may result in an alteration in shape of the dendritic spines in 
Table 1. Genes and loci implicated in the pathogenesis of auditory neuropathy (AN) with corresponding phenotypes

\begin{tabular}{|c|c|c|c|c|c|}
\hline Syndrome name & Locus & Gene & Transmission & Phenotype & Reference \\
\hline \multicolumn{6}{|l|}{ Isolated AN } \\
\hline & $2 p 23-p 22$ & OTOF & Recessive & Congenital profound deafness & {$[9,12]$} \\
\hline & $2 q 31.1-q 31.3$ & PJVK & Recessive & Congenital profound deafness & [17] \\
\hline \multirow[t]{2}{*}{ AUNA1 } & $13 q 21-q 24$ & DIAPH3 & Dominant & Moderate to profound deafness & {$[11,20]$} \\
\hline & mtDNA & $12 S$ rRNA (T1095C) & & Moderate deafness & [23] \\
\hline \multicolumn{6}{|l|}{ Non-isolated AN } \\
\hline CMT 1A & $17 p 11.2-p 12$ & PMP22 & Dominant & Mild to severe deafness; demyelinating neuropathy & [25] \\
\hline CMT 1B & $1 q 22$ & $M P Z$ & Dominant & Mild to severe deafness; demyelinating neuropathy & [24] \\
\hline CMT 2E & $8 p 21$ & $N F-L$ & Dominant & Normal hearing; axonal neuropathy & [29] \\
\hline CMT 4D & $8 q 24.3$ & NDRG1 & Recessive & Mild to severe deafness; axonal/demyelinating neuropathy & {$[26,27]$} \\
\hline CMT & $1 \mathrm{p} 34$ & GJB3 (CX31) & Dominant & Mild deafness & [30] \\
\hline CMT $1 X$ & Xp13 & GJB1 (CX32) & X-linked Dominant & Demyelinating neuropathy & [31] \\
\hline ADOA & $3 q 28-q 29$ & OPA1 (R445H) & Dominant & Optic neuropathy; moderate deafness & [36] \\
\hline AROA & $1 \mathrm{q} 14.1-11 \mathrm{q} 22.3$ & TMEM126A & Recessive & Optic neuropathy; mild hearing loss & [42] \\
\hline Friedreich's ataxia & $9 q 13$ & FXN & Recessive & $\begin{array}{l}\text { Ataxia; axonal neuropathy; optic neuropathy; } \\
\text { cardiomyopathy; normal hearing threshold; mild deafness }\end{array}$ & [43] \\
\hline AUNX1 & Xq23-q27.3 & & X-linked Recessive & Sensory axonal neuropathy; mild-to-severe deafness & [46] \\
\hline DDON (Mohr-Tranebjaerg) & Xq22.1 & TIMM8A & X-linked Recessive & Progressive deafness; dystonia, optic neuropathy; dementia & [45] \\
\hline Wolfram & $4 p 16.1$ & WFS1 & Recessive & Optic atrophy, diabetes, progressive deafness, dementia & [47] \\
\hline LHON (Leber) & mtDNA & \multicolumn{2}{|l|}{ MTND4 (11778mtDNA) } & Optic neuropathy; mild-to-moderate deafness & [41] \\
\hline
\end{tabular}

ADOA, autosomal dominant optic atrophy; AROA, autosomal recessive optic atrophy; AUNA1, Autosomal dominant auditory neuropathy; AUNX1, auditory neuropathy, X-linked recessive; CMT, Charcot-Marie-Tooth; DDON, deafness dystonia optic neuronopathy; LHON, Leber's hereditary optic neuropathy.

the distal portions of auditory nerve fibers [22] and delayed impairment of hair-cell function, leading to profound deafness and disappearance of OAEs over time.

A mutation (T1095C) in a highly conserved region of the mitochondrial $12 \mathrm{~S}$ rRNA gene has been identified in a Chinese patient with moderate deafness and showing the picture of isolated AN [23]. It has been hypothesized that the phenotypic expression of this mutation was influenced by two more genetic variants identified in the same gene in a highly conserved region.

\section{Genes involved in non-isolated AN}

It has been estimated that over one third of subjects with AN are affected by peripheral neuropathies [6]. In addition, optic neuropathies and other CNS disorders have been found in association with AN (non-isolated AN, Table 1). In this group of subjects the hearing disorder is underlain by several genetic defects, all resulting in neuronal loss and demyelination in peripheral and/or cranial nerves, and the site of the lesion is invariably postsynaptic.

AN has been identified at relatively high frequency in patients affected by Charcot-Marie-Tooth (CMT) disease. The first gene associated with $\mathrm{AN}$ in this group was the myelin protein zero (MPZ) gene [24] encoding a protein included in the compact myelin that plays a crucial role in myelin formation and adhesion. A missense mutation in $M P Z$ was identified in a family affected by dominant $\mathrm{AN}$ and demyelinating sensorimotor neuropathy [24]. Post-mortem examination carried out on one member of this family revealed preserved hair cells in the cochlea, a marked decrease in spiral ganglion cell number and extensive degeneration of both peripheral and central processes in the residual axons. Moreover, the proximal portion of the auditory nerve showed axonal loss and incomplete remyelination at the entrance to the brainstem similar to that found on histological examination of the sural nerve in the same patient. Notice that the patient was affected by peripheral neuropathy and thus postmortem examination was carried out on both cranial and peripheral nerves. These findings are relevant as they confirm the hypothesis that both axonal loss and demyelination of auditory nerve fibers underlie the disruption of temporal coding of acoustic signals through reduced input and slowed conduction of action potentials. The involvement of the entire auditory nerve associated with hair-cell preservation is likely to be a feature shared by the majority of AN disorders included in the CMT group. This has implications for the outcome of cochlear implantation, as 
decreased responsiveness to electrical stimulation and delayed conduction of neural impulses in residual auditory nerve fibers are expected. A point mutation of the PMP22 gene, which encodes another protein included in compact myelin, has been found in a family whose affected members showed demyelinating neuropathy associated with the clinical picture of AN [25].

Two more genes associated with the CMT group of AN are of particular interest. One is the N-myc downstreamregulated gene 1 (NDRG1), which encodes a protein that shuttles between the cytoplasm and the nucleus in Schwann cells and has been implicated in cell differentiation and maintenance [26]. Point mutations in NDRG1 underlie a recessive axonal and demyelinating sensorimotor neuropathy which has been associated with the picture of AN [26,27]. Another gene associated with AN is $N F-L$, which is involved in the molecular processes underlying neuronal plasticity by encoding a protein involved in axonal sprouting [28]. Two different point mutations have recently been identified in NF- $L$ in two Slovenian families whose members were affected by axonal neuropathy [29]. One of these families presented with the picture of AN. Interestingly, the affected members showed abnormal auditory brainstem responses associated with OAE detection but without impairment of speech perception and gap detection abilities. Although mutations in both GJB1 and GJB3 (which encode gap junction proteins) have been associated with AN $[30,31]$, the reported evidence does not allow us to definitely identify the AN pattern in the affected patients described so far.

Several types of optic neuropathies have proved to be associated with AN. Among these, autosomal dominant optic atrophy is underlain by mutations in the OPA1 gene, which encodes a dynamin-related mitochondrial GTPase involved in the regulation of oxidative phosphorylation [32], mitochondrial fusion [33], maintenance of integrity of mitochondrial cristae [34], and control of apoptosis [35]. To date, AN has been associated only with the Arg445 to His $(\mathrm{R} 445 \mathrm{H})$ mutation [10,36], although sensorineural hearing loss has been reported in more than 50\% of patients carrying OPA1 mutations [37]. Unfortunately, no extensive audiological and electrophysiological studies were carried out in the majority of affected subjects to better characterize the hearing disorder. Combined electrophysiological and audiological evaluation on two related patients carrying the $\mathrm{R} 445 \mathrm{H}$ mutation [10] suggest that the lesion involves the distal portion of auditory nerve fibers. This hypothesis is supported by a mouse model of OPA1 showing dendritic pruning of the optic nerve fibers at the early stage of the disease [38]. Extensive demyelination of the entire optic and auditory nerves has been found on post-mortem examination in two elderly patients with advanced disease [39]. These findings, together with the loss of retinal ganglion cells and degeneration of residual axons found in another mouse model [40], would suggest that demyelination and axonal loss affecting the whole optic and auditory nerves constitutes a more advanced stage of the disease compared to the stage of dendritic tree pruning [38].

Auditory neuropathy has also been well documented in two patients with Leber's hereditary optic neuropathy, which is underlain by a mitochondrial point mutation [41], and in patients with autosomal recessive optic atrophy due to nonsense mutations of the TMEM126A gene encoding a mitochondrial protein [42]. In general, the association of optic and auditory neuropathies in patients with abnormal mitochondrial function may be considered in the light of the high metabolic demands of specific neural structures such as the unmyelinated portion of both optic and auditory nerve fibers. Unlike in myelinated axons, in which the conduction of impulses is saltatory, electrical conduction in the unmyelinated fibers is electrotonic and energy consuming.

Impairment of speech perception has been found with high frequency in patients affected by Friedreich's ataxia and has been related to AN [43]. Friedreich's ataxia is underlain by a GAA trinucleotide repeat expansion in the FXN gene with consequent reduction of gene expression, which results in mitochondrial iron overload [44] in both peripheral nerves and the CNS. The majority of patients with Friedreich's ataxia show a picture of AN with normal hearing threshold and remarkable decrease in speech perception abilities [43].

Among the multisystem disorders, the Mohr-Tranebjaerg syndrome (deafness dystonia optic neuronopathy) provides a good example of AN that has been assessed on a histopathologic basis. Post-mortem specimens obtained from four patients with AN [45] revealed extensive loss of spiral ganglion neurons with preservation of hair cells. Neuronal loss in these patients is expected to be due to the abnormal function of a protein encoded by the TIMM $8 \mathrm{~A}$ gene on the $\mathrm{X}$ chromosome and embedded in the inner mitochondrial membrane. The $\mathrm{X}$ chromosome also contains the locus underlying AN in a large Chinese family whose members are affected by postlingual hearing loss and progressive peripheral sensory neuropathy [46]; however, the underlying gene has not yet been identified.

Finally, AN has been identified on a histopathologic basis in young patients with Wolfram syndrome [47]. Post-mortem examination showed extensive phenomena of brain atrophy and axonal loss involving both auditory and optic nerves.

\section{Mechanisms underlying auditory neuropathy}

Figure 1 illustrates schematically the possible pathophysiological mechanisms underlying genetically based AN. In 

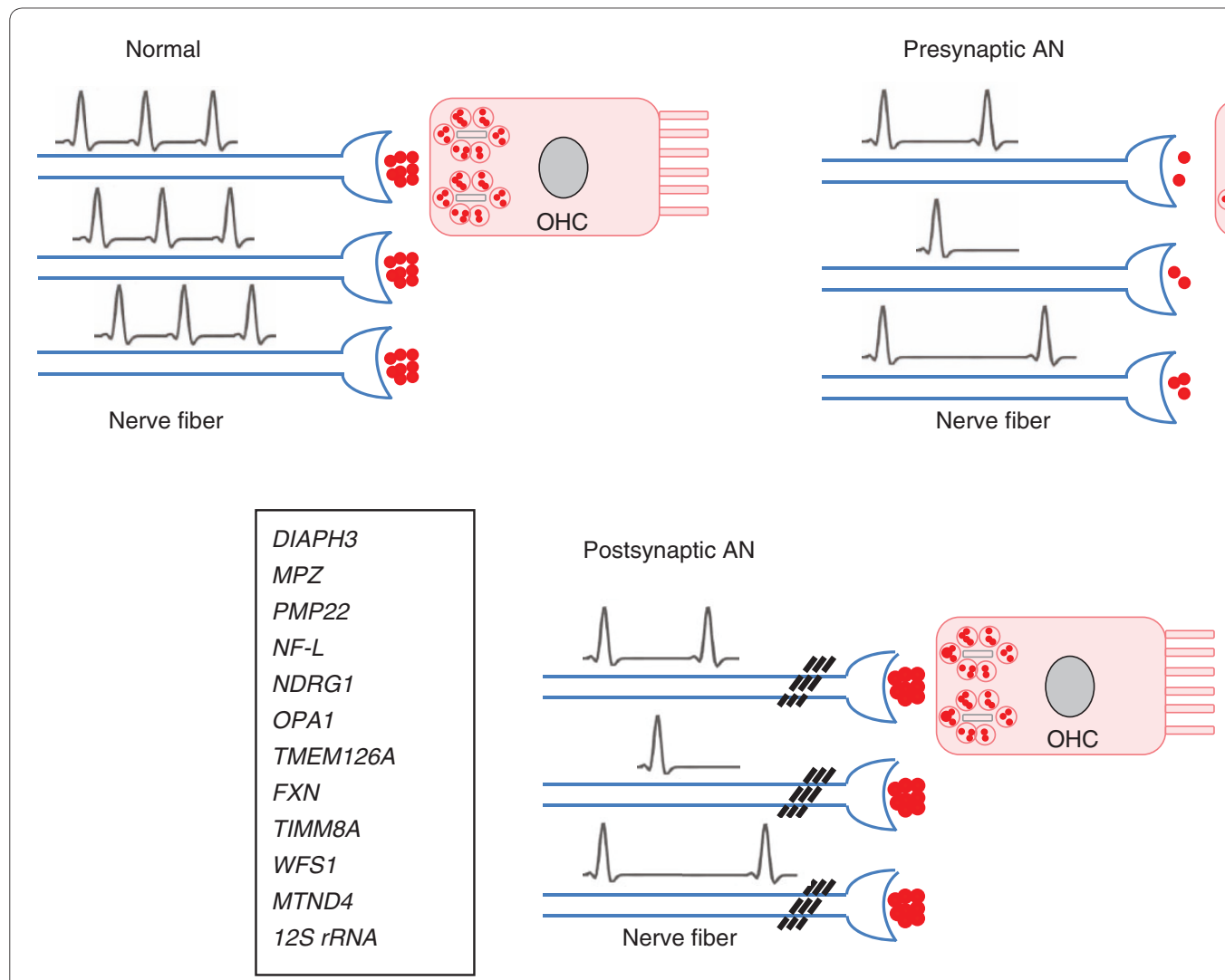

Figure 1. Possible mechanisms underlying presynaptic or postsynaptic auditory neuropathy. In the healthy cochlea (Normal) an auditory input transmitted from an outer hair cell $(\mathrm{OHC})$ evokes a synchronized discharge of auditory nerve fibers. In presynaptic AN, both the reduction and the increased time of neurotransmitter release result in decreased postsynaptic activation (decreased input) and elicitation of EPSPS with abnormal morphology leading, in turn, to a reduction of occurrence of and increased time to spike initiation (desynchrony). This mechanism is likely to underlie AN in patients carrying OTOF mutations. In postsynaptic AN, there is a decrease in activated auditory fibers (decreased input), abnormalities in spike occurrence with slowing in conduction velocity, which results in loss of temporal precision and stimulus correlation of auditory nerve fiber discharge (desynchrony). Genes implicated in pre- and postsynaptic AN, respectively, are shown in the boxes.

AN, auditory perceptions relying on temporal cues are impaired because of the disruption of temporal coding of acoustic signals [8]. In the healthy cochlea, temporal precision of acoustic signaling is guaranteed by the fast kinetics of synaptic release, postsynaptic membrane activation, and the initiation and propagation of spikes along the auditory nerve fibers [48]. Fast vesicle release, which is triggered by calcium influx through one or two calcium channels [49], tight coupling of these channels to the vesiclerelease sites [49], and parallel release of multiple vesicles through the ribbons [50], all ensure high rate and temporal precision of release of the neurotransmitter glutamate. In particular, multivesicular release guarantees the generation of excitatory postsynaptic potentials (EPSPs) of sufficient amplitude to trigger spike initiation in the auditory nerve fibers [48]. The disruption of any of these presynaptic mechanisms impairs the precision of temporal coding and/ or the reliability of synaptic transmission with consequent decrease in the amplitude and rise time of EPSPs.
A typical example of presynaptic disorder leading to the clinical picture of AN is that caused by the abnormal function of otoferlin. Reduced activity of this protein leads to a reduced rate of vesicle replenishment [51], which in the healthy cochlea is a very fast process, and abolition of the fast phase of exocytosis [15]. The decrease in neurotransmitter release is likely to result in a decrease in amplitude of EPSPs with decreased synaptic reliability. This may explain why patients with mutations in $O T O F$ usually present with profound hearing loss. Nevertheless, the slow component of exocytosis is not abolished [15], while recordings of cochlear neural potentials from patients with $O T O F$ mutations ([52], see below) point to activation of the postsynaptic membrane. Given this, it could be hypothesized that, besides the reduction of neurotransmitter availability at the synaptic cleft, there is an impairment of multivesicular release which leads to the generation of small EPSPs with abnormal morphology and dispersed in time. These 
EPSPs may occasionally trigger action potentials, which are expected to be poorly related to acoustic stimuli. This hypothesis is supported by the identification of some patients with OTOF mutations who show almost normal hearing thresholds together with severe impairment of speech perception (R. Santarelli et al., manuscript in preparation).

Although PJVK protein has been localized in hair cells, supporting cells and spiral ganglion neurons, its function remains unknown; thus, it is not possible to suggest any mechanisms underlying $\mathrm{AN}$ in patients with mutations in the PJVK gene.

In the healthy cochlea, both the postsynaptic membrane and the auditory nerve fibers are adapted for fast and precise signal transmission. Like the synapses between rods and bipolar cells in the optic nerve, AMPA receptors on the postsynaptic membrane of auditory nerve fibers show low affinity for glutamate [53]. This results in rapid activation and deactivation of the postsynaptic membrane, while the low tendency to receptor desensitization ensures that the nerve fibers retain their sensitivity in spite of the high amounts of glutamate released in the synaptic cleft [48]. Moreover, the abundance of Nav1.6 sodium channels and their strategic disposition along the nerve fibers enhances the velocity and precision of spike initiation and propagation [54].

The demyelination of auditory nerve fibers observed in demyelinating neuropathies is expected to result in slowed conduction velocity with consequent disruption of temporal coding of acoustic signals (desynchrony) [8], while the decrease in number of nerve fibers found in axonal neuropathies would result in a reduced auditory input to the brainstem. However, this is a simplified view of the alterations of auditory nerve discharge, as slowing of conduction velocity and reduction of neural fiber recruitment might interact and disrupt the 'spectrum' of discharges of auditory nerve fibers activated by a specific acoustic signal. Moreover, it is reasonable to hypothesize that the residual axons are not functioning properly, as they show abnormal spike initiation and conduction. All these mechanisms are likely to be involved in the pathophysiology of several axonal and demyelinating auditory neuropathies such as those underlain by mutations in the MPZ, PMP22 and NDRG1 genes.

In general, all the genetic disorders leading to an abnormal mitochondrial function cause dysfunction of the unmyelinated portion of auditory nerve fibers, which may represent the first sign of disease. This is likely to result from the high metabolic demands of unmyelinated axons for spike conduction. Abnormalities of the distal portion of auditory nerve fibers have been hypothesized as underlying $\mathrm{AN}$ in patients carrying the OPA1 mutation $[11,20]$, and dendritic pruning of optic nerve fibers is the first sign of disease in animal models of OPA1 [38].
It is important to emphasize that the AN associated with specific gene mutations may be caused by several mechanisms interacting with each other, and the distinction between pre- and postsynaptic AN should be treated with caution. For instance, demyelination and axonal loss have been found in the advanced stages of disease due to mutant OPA1 [39] and in some experimental models of OPA1 [40]; this indicates that dendritic dysfunction is not the only mechanism involved in the pathophysiology of AN in these gene disorders. Moreover, some forms of AN showing postsynaptic dysfunction as the first sign of disease may turn into disorders with prevalent presynaptic involvement. For instance, patients carrying the DIAPH3 mutation show moderate hearing loss associated with severe impairment of speech perception [11], which has been explained as resulting from dysfunction of the dendritic spines contacting the IHCs $[11,20]$. Thereafter, the hearing impairment progresses to profound deafness and OAEs disappear [11]. At this late stage, there is likely to be involvement of the stereocilia in both IHCs and OHCs, as the DIAPH3 gene is known to regulate the activity of presynaptic actin and microtubule cytoskeletons in the neuromuscular junction of Drosophila [55].

\section{Diagnosis of auditory neuropathy: a true challenge}

In AN, the impairment of spike initiation, reduced auditory input due to axonal loss, and slowing in conduction velocity related to demyelination of residual nerve fibers result in disruption of auditory nerve discharge and auditory brainstem response abnormalities beyond those expected from the hearing loss [1]. The same pathological processes underlie the impairment of speech perception, which is reduced out of proportion to the elevation in hearing threshold. In general, affected subjects show decreased performance in all the auditory tasks that rely on temporal coding of acoustic signals such as gap detection and low-frequency discrimination [8]. OAEs are detected in typical cases as long as OHCs are preserved. If all these findings are present, the diagnosis of AN is straightforward, particularly in the presence of concomitant peripheral and/or optic neuropathy. Moreover, the identification of specific gene mutations may help to localize the lesion and has implications for rehabilitation, which sees cochlear implantation as the only tool for the restoration of speech perception by bypassing the site of the lesion.

However, OAEs are absent in more than a third of patients on re-testing [1], and impairment of speech perception may be apparent only in the presence of noise [1]. Moreover, no detailed information of cochlear nerve and hair-cell activities can be provided by auditory brainstem response recording because of the low signalto-noise ratio. Recently, the use of transtympanic 
electrocochleography has been proposed to define the details of cochlear potentials including both receptor activities (measured as summating potential and cochlear microphonics) and auditory nerve activities (measured as the compound action potential) [56]. Figure 2 shows two transtympanic electrocochleogram patterns obtained from patients with AN who each carried a mutation in a different gene: OTOF [52] and OPA1 [10]. The cochlear potentials observed in response to clicks were superimposed on the grand average of the summating potential-compound action potential responses obtained from 16 controls with normal hearing at $120 \mathrm{~dB}$ peakequivalent sound pressure level. In controls, the summating potential was followed by a straight neural response with mean latency of $1.5 \mathrm{~ms}$. In patients with OPA1 or OTOF mutations, the responses arising in the auditory nerve consisted of negative potentials with reduced amplitude, increased latency and prolonged duration compared to controls. Nevertheless, several differences between OPA1 and OTOF subjects were found. First, the prolonged potentials were recorded as low as 50-90 $\mathrm{dB}$ below behavioral thresholds in subjects with $O T O F$ mutations, whereas in the OPA1 disorder they were correlated with hearing threshold (not shown). Moreover, a low-amplitude compound action potential was superimposed on the prolonged responses at high stimulus intensity in the subject with biallelic OTOF mutation, while no such potential was identified in the OPA1 patient. Finally, electrically evoked compound action potentials were recorded after cochlear implantation only from the child carrying biallelic mutation in the OTOF gene. From these observations it can be hypothesized that the low-threshold prolonged potentials recorded in $O T O F$ disorders are related to abnormal neurotransmitter release resulting in reduced dendritic activation and impairment of spike initiation, whereas the lack of both acoustically and electrically evoked compound action potentials in the OPA1 disorder is consistent with abnormal function of the distal portions of auditory nerve fibers.

In conclusion, the diagnosis of AN relies on objective tests as well as on tests requiring the cooperation of the patient. However, it is the whole body of findings collected using several techniques that contributes to defining the disorder and helps to localize the underlying lesion. The correlation between electrophysiological and

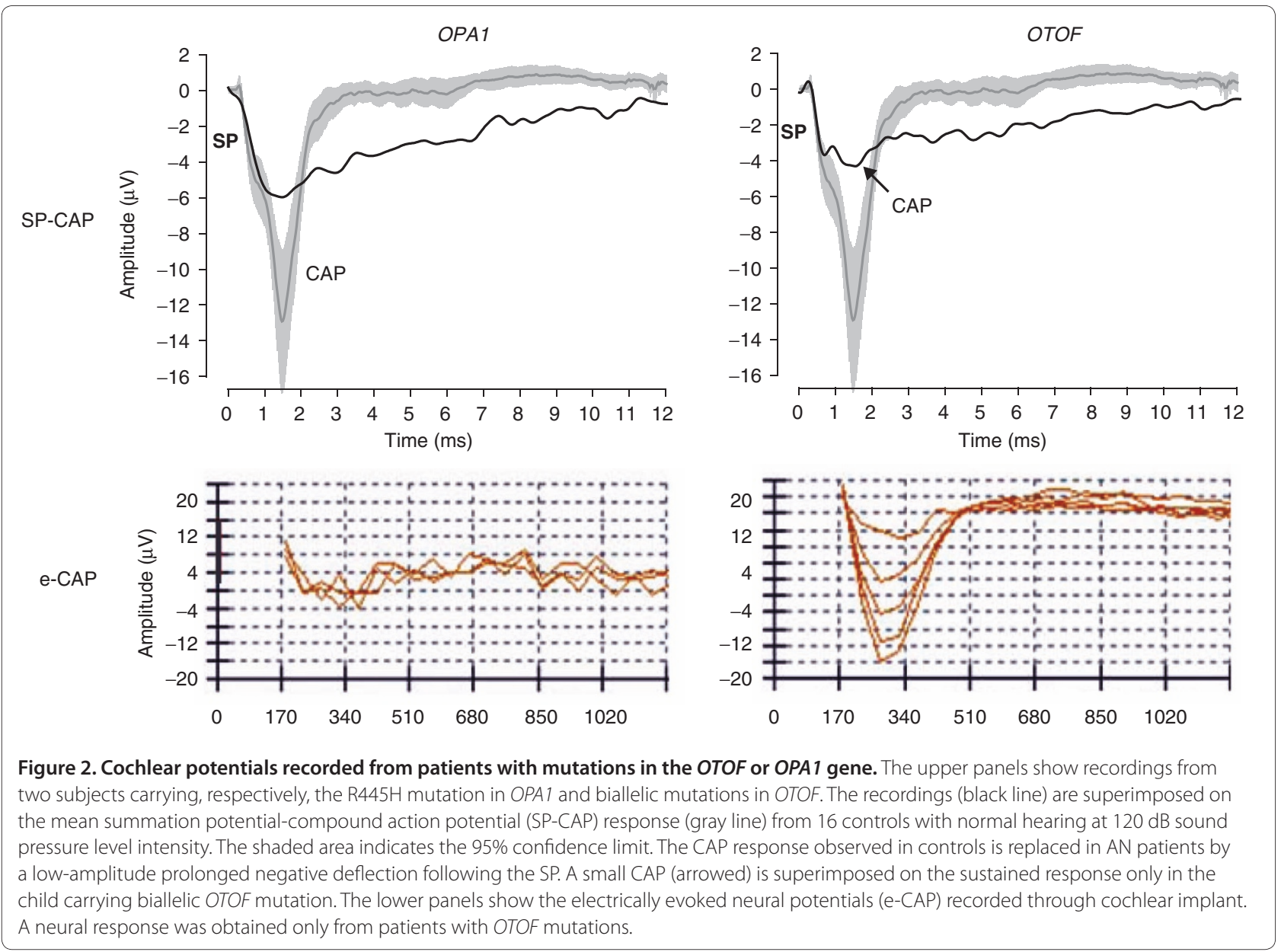


genetic evaluation helps to localize the site of lesion and clarify the mechanisms underlying AN in individual patients. For instance, a picture of profound hearing loss associated with the presence of slow negative components at low stimulation intensities in electrocochleography recordings points to a presynaptic disorder with reduced dendritic activation and preserved function of auditory nerve fibers. A severe visual impairment associated with the AN picture and the presence of slow negative potentials in electrocochleogram waveforms at intensities related to hearing thresholds suggests a postsynaptic disorder involving the distal portions of auditory nerve fibers, possibly underlain by an OPA1 mutation or a mitochondrial disorder.

The identification of specific mutations underlying AN has implications not only for diagnosis but also for rehabilitation, as cochlear implantation is expected to have a good outcome when the disorder is due to mutations underlying presynaptic $(O T O F)$ and postsynaptic (OPA1 and DIAPH3) disorders in the distal portions of auditory fibers. In contrast, cochlear implantation is expected to have little benefit in forms of AN involving the entire auditory nerve.

\section{Future developments}

Auditory neuropathies constitute a fascinating group of hearing dysfunctions in that the definition of their pathophysiology and site of lesion involves the collection of findings from psychoacoustics, evoked-potential recordings, genetics, molecular biology and animal models. Identification of mutations in specific genes associated with typical electrophysiological patterns and the comparison of these findings with those obtained from animal models may be the key factor in revealing how the failure of different molecular processes underlies the varieties of AN. Studies focusing on the function of proteins encoded by specific genes at cellular level, the effects of abnormal functions of these proteins in animal models, the combination of information from basic research with audiological and electrophysiological findings in patients carrying mutations in specific genes, are all expected to improve diagnosis in the near future with regard to both site of lesion and mechanisms involved. In particular, the use of electrocochleographic recordings could help in bridging knowledge from basic research and clinical evaluation. Improvements of this technique from the point of view of frequency selectivity and recording from a small group of fibers together with the combination of the electrocochleogram results with those provided by electrically evoked potential recordings would contribute to better characterization of the lesion in the auditory periphery.

A second crucial point would be to perform brainimaging studies aimed at identifying specific brain regions with abnormal responses to specific stimuli such as speech in noise, brief silent periods in noise, and sounds with different frequency content. Finally, it remains to be assessed whether different mutations of the same gene result in similar phenotypes, or whether differences in amounts and activity of the synthesized protein, if present, might result in different patterns of auditory nerve discharge. In other words, knowledge from basic research should be combined with clinical, audiological, psychoacoustical, electrophysiological, and imaging studies in humans to characterize the lesion at the level of the auditory periphery and the changes induced in auditory brain areas by the abnormal input from lower auditory centers.

The only effective treatment for restoration of speech perception in AN is cochlear implantation. However, the outcome of cochlear implantation varies widely among patients. While it is generally acknowledged that patients with presynaptic AN due to mutations in the OTOF gene invariably benefit [9], a poor outcome has been reported for implanted subjects with postsynaptic AN underlain by axonal loss and degeneration of the entire nerve fibers, as in Friedreich ataxia [57] and deafness dystonia optic neuronopathy [58]. In contrast, two patients carrying the $\mathrm{R} 445 \mathrm{H}$ mutation in the OPA1 gene [10] and some subjects with mutations in the DIAPH3 gene [11] showed restoration of both speech perception and auditory brainstem responses following cochlear implantation. In these subjects the electrical stimulation provided through the cochlear implant is presumed to bypass the site of the lesion, which is limited to the terminal dendrites. In this view, the identification of specific genetic mutations is crucial to deciding whether to perform cochlear implantation. However, whether or not specific strategies of electrical stimulation possibly tailored on the abnormal discharge of demyelinated fibers could improve speech perception in implanted patients with demyelinating-axonal neuropathies remains to be assessed. Recently, children with Friedreich's ataxia have received significant benefit from using an FM-listening device in everyday life and in speech perception performance [59]. FM-systems transmit the speech signals detected by a microphone, which is worn by the speaker, to the ear receivers worn by the listeners. In this regard, a further possibility worth exploring as a rehabilitative strategy is pre-processing of acoustic signals to make them more suited for eliciting a 'meaningful' input from the auditory periphery.

In conclusion, the combination of findings from genetic research and highly sensitive neurophysiologic recordings will help clarify both the mechanisms and the anatomical sites underlying the disruption of temporal coding of sounds in auditory nerve fibers that is typical of AN. 


\section{Abbreviations}

ADOA, autosomal dominant optic atrophy; AMPA, a-amino-3-hydroxy-5methyl-4-isoxazolepropionic acid; AN, auditory neuropathy; AROA, autosomal recessive optic atrophy; AUNA1, auditory neuropathy, autosomal dominant 1 ; AUNX1, auditory neuropathy, X-linked recessive; CMT, Charcot-Marie Tooth: DDON, deafness dystonia optic neuronopathy; EPSPS, excitatory postsynaptic potentials; IHCs, inner hair cells; LHON, Leber's hereditary optic neuropathy; OAEs, otoacoustic emissions; OHCs, outer hair cells.

\section{Author information}

$\mathrm{RS}$ is an assistant professor at the University of Padua in the Service of Audiology and Phoniatrics located in Treviso Regional Hospital. She performs audiological and electrophysiological evaluation of patients with hearing impairment. The main focus of research is on the electrophysiological findings from patients with auditory neuropathy.

\section{Competing interests}

The author declares that she has no competing interests.

\section{Acknowledgements}

The author is deeply grateful to Arnold Starr for his criticism of the manuscript. She is also grateful to Ignacio del Castillo, Taosheng Hang and Edoardo Arslan for their contribution to AN research. She thanks colleagues, technicians, secretaries and nurses working at the Service of Audiology and Phoniatrics in Treviso Hospital for their support in clinical evaluation of patients with AN.

Published: 22 December 2010

\section{References}

1. Starr A, Zeng F, Michalewski H, Moser T: Perspectives on auditory neuropathy: disorders of inner hair cell, auditory nerve, and their synapse. In The Senses: A Comprehensive Reference. Edited by Basbaum Al et al. New York: Academic Press; 2008:397-412.

2. Probst R, Lonsbury-Martin BL, Martin GK: A review of otoacoustic emissions. J Acoust Soc Am 1991, 89:2027-2067.

3. Dallos P, Wang CY: Bioelectric correlates of kanamycin intoxication. Audiology 1974, 13:277-289.

4. Johnson JS, Newport EL: Critical period effects on universal properties of language: the status of subjacency in the acquisition of a second language. Cognition 1991, 39:215-258.

5. Starr, A, Kaga, K: Neuropathies of the Auditory and Vestibular Eighth Cranial Nerves. Tokyo: Springer Publishing; 2009

6. Berlin Cl, Hood LJ, Morlet T, Wilensky D, Li L, Mattingly KR, Taylor-Jeanfreau J, Keats BJB, John PS, Montgomery E, Shallop JK, Russell BA, Frisch SA: Multi-site diagnosis and management of 260 patients with auditory neuropathy/ dys-synchrony (auditory neuropathy spectrum disorder). Int J Audio/ 2010 49:30-43.

7. Year 2007 position statement: principles and guidelines for early hearing detection and intervention programs: Pediatrics 2007, 120:898-921.

8. Zeng F, Kong Y, Michalewski HJ, Starr A: Perceptual consequences of disrupted auditory nerve activity. J. Neurophysiol 2005, 93:3050-3063.

9. Rodríguez-Ballesteros M, del Castillo FJ, Martín Y, Moreno-Pelayo MA, Morera C, Prieto F, Marco J, Morant A, Gallo-Terán J, Morales-Angulo C, Navas C, Trinidad G, Tapia MC, Moreno F, del Castillo I: Auditory neuropathy in patients carrying mutations in the otoferlin gene (OTOF). Hum Mutat 2003, 22:451-456

10. Huang T, Santarelli R, Starr A: Mutation of OPA1 gene causes deafness by affecting function of auditory nerve terminals. Brain Res 2009, 1300:97-104.

11. Starr A, Isaacson B, Michalewski HJ, Zeng F, Kong Y, Beale P, Paulson GW, Keats $B J B$, Lesperance MM: A dominantly inherited progressive deafness affecting distal auditory nerve and hair cells. J Assoc Res Otolaryngo/ 2004, 5:411-426.

12. Varga R, Kelley PM, Keats BJ, Starr A, Leal SM, Cohn E, Kimberling WJ: Nonsyndromic recessive auditory neuropathy is the result of mutations in the otoferlin (OTOF) gene. J Med Genet 2003, 40:45-50.

13. Rodríguez-Ballesteros M, Reynoso R, Olarte M, Villamar M, Morera C, Santarelli R. Arslan E, Medá C, Curet C, Völter C, Sainz-Quevedo M, Castorina P, Ambrosetti U, Berrettini S, Frei K, Tedín S, Smith J, Cruz Tapia M, Cavallé L, Gelvez N, Primignani P, Gómez-Rosas E, Martín M, Moreno-Pelayo MA, Tamayo M, Moreno-Barral J, Moreno F, del Castillo I: A multicenter study on the prevalence and spectrum of mutations in the otoferlin gene (OTOF) in subjects with nonsyndromic hearing impairment and auditory neuropathy. Hum Mutat 2008, 29:823-831.

14. Rizo J, Südhof TC: C2-domains, structure and function of a universal Ca2+-binding domain. J Biol Chem 1998, 273:15879-15882.

15. Roux I, Safieddine S, Nouvian R, Grati M, Simmler M, Bahloul A, Perfettini I, Le Gall M, Rostaing P, Hamard G, Triller A, Avan P, Moser T, Petit C: Otoferlin, defective in a human deafness form, is essential for exocytosis at the auditory ribbon synapse. Cell 2006, 127:277-289.

16. Pangrsic T, Lasarow L, Reuter K, Takago H, Schwander M, Riedel D, FrankT, Tarantino LM, Bailey JS, Strenzke N, Brose N, Müller U, Reisinger E, Moser T: Hearing requires otoferlin-dependent efficient replenishment of synaptic vesicles in hair cells. Nat Neurosci 2010, 13:869-876.

17. Delmaghani S, del Castillo FJ, Michel V, Leibovici M, Aghaie A, Ron U, Van Laer L, Ben-Tal N, Van Camp G, Weil D, Langa F, Lathrop M, Avan P, Petit C: Mutations in the gene encoding pejvakin, a newly identified protein of the afferent auditory pathway, cause DFNB59 auditory neuropathy. Nat Genet 2006, 38:770-778

18. Collin RWJ, Kalay E, Oostrik J, Caylan R, Wollnik B, Arslan S, den Hollander Al, Birinci Y, Lichtner P, Strom TM, Toraman B, Hoefsloot LH, Cremers CWRJ, Brunner HG, Cremers FPM, Karaguzel A, Kremer H: Involvement of DFNB59 mutations in autosomal recessive nonsyndromic hearing impairment. Hum Mutat 2007, 28:718-723.

19. Ebermann I, Walger M, Scholl HPN, Charbel Issa P, Lüke C, Nürnberg G, LangRoth R, Becker C, Nürnberg P, Bolz HJ: Truncating mutation of the DFNB59 gene causes cochlear hearing impairment and central vestibular dysfunction. Hum Mutat 2007, 28:571-577

20. Schoen CJ, Emery SB, Thorne MC, Ammana HR, Sliwerska E, Arnett J, Hortsch M, Hannan F, Burmeister M, Lesperance MM: Increased activity of Diaphanous homolog 3 (DIAPH3)/diaphanous causes hearing defects in humans with auditory neuropathy and in Drosophila. Proc Natl Acad Sci USA 2010, 107:13396-13401.

21. Wallar BJ, Alberts AS: The formins: active scaffolds that remodel the cytoskeleton. Trends Cell Biol 2003, 13:435-446.

22. Hotulainen P, Llano O, Smirnov S, Tanhuanpää K, Faix J, Rivera C, Lappalainen $P$ : Defining mechanisms of actin polymerization and depolymerization during dendritic spine morphogenesis. J Cell Biol 2009, 185:323-339.

23. Wang Q, Li R, Zhao H, Peters JL, Liu Q, Yang L, Han D, Greinwald JH, Young W, Guan M: Clinical and molecular characterization of a Chinese patient with auditory neuropathy associated with mitochondrial 12S rRNA T1095C mutation. Am J Med Genet A 2005, 133A:27-30.

24. Starr A, Michalewski HJ, Zeng F, Fujikawa-Brooks S, Linthicum F, Kim CS, Winnier D, Keats B: Pathology and physiology of auditory neuropathy with a novel mutation in the MPZ gene (Tyr145->Ser). Brain 2003, 126:1604-1619.

25. Kovach MJ, Campbell KCM, Herman K, Waggoner B, Gelber D, Hughes LF, Kimonis VE: Anticipation in a unique family with Charcot-Marie-Tooth syndrome and deafness: delineation of the clinical features and review of the literature. Am J Med Genet 2002, 108:295-303.

26. Kalaydjieva L, Gresham D, Gooding R, Heather L, Baas F, de Jonge R, Blechschmidt K, Angelicheva D, Chandler D, Worsley P, Rosenthal A, King RH, Thomas PK: N-myc downstream-regulated gene 1 is mutated in hereditary motor and sensory neuropathy-Lom. Am J Hum Genet 2000, 67:47-58.

27. Butinar D, Zidar J, Leonardis L, Popovic M, Kalaydjieva L, Angelicheva D, Sininger Y, Keats B, Starr A: Hereditary auditory, vestibular, motor, and sensory neuropathy in a Slovenian Roma (Gypsy) kindred. Ann Neurol 1999, 46:36-44.

28. Illing RB: Activity-dependent plasticity in the adult auditory brainstem. Audiol Neurootol 2001, 6:319-345.

29. Butinar D, Starr A, Zidar J, Koutsou P, Christodoulou K: Auditory nerve is affected in one of two different point mutations of the neurofilament light gene. Clin Neurophysiol 2008, 119:367-375.

30. López-Bigas N, Olivé M, Rabionet R, Ben-David O, Martínez-Matos JA, Bravo O, Banchs I, Volpini V, Gasparini P, Avraham KB, Ferrer I, Arbonés ML, Estivill X: Connexin 31 (GJB3) is expressed in the peripheral and auditory nerves and causes neuropathy and hearing impairment. Hum Mol Genet 2001 10:947-952.

31. Bähr M, Andres F, Timmerman V, Nelis ME, Van Broeckhoven C, Dichgans J: Central visual, acoustic, and motor pathway involvement in a CharcotMarie-Tooth family with an Asn205Ser mutation in the connexin 32 gene. J Neurol Neurosurg Psychiatr 1999, 66:202-206

32. Lodi R, Carelli V, Cortelli P, lotti S, Valentino ML, Barboni P, Pallotti F, Montagna 
P, Barbiroli B: Phosphorus MR spectroscopy shows a tissue specific in vivo distribution of biochemical expression of the G3460A mutation in Leber's hereditary optic neuropathy. J Neurol Neurosurg Psychiatr 2002, 72:805-807.

33. Lee Y, Jeong S, Karbowski M, Smith CL, Youle RJ: Roles of the mammalian mitochondrial fission and fusion mediators Fis1, Drp1, and Opa1 in apoptosis. Mol Biol Cell 2004, 15:5001-5011.

34. Griparic L, van der Wel NN, Orozco IJ, Peters PJ, van der Bliek AM: Loss of the intermembrane space protein Mgm1/OPA1 induces swelling and localized constrictions along the lengths of mitochondria. J Biol Chem 2004, 279:18792-18798

35. Frezza C, Cipolat S, Martins de Brito O, Micaroni M, Beznoussenko GV, Rudka T, Bartoli D, Polishuck RS, Danial NN, De Strooper B, Scorrano L: OPA1 controls apoptotic cristae remodeling independently from mitochondrial fusion. Cell 2006, 126:177-189.

36. Amati-Bonneau P, Guichet A, Olichon A, Chevrollier A, Viala F, Miot S, Ayuso C, Odent S, Arrouet C, Verny C, Calmels M, Simard G, Belenguer P, Wang J, Puel J, Hamel C, Malthièry Y, Bonneau D, Lenaers G, Reynier P: OPA1 R445H mutation in optic atrophy associated with sensorineural deafness. Ann Neurol 2005, 58:958-963.

37. Yu-Wai-Man P, Griffiths PG, Gorman GS, Lourenco CM, Wright AF, AuerGrumbach M, Toscano A, Musumeci O, Valentino ML, Caporali L, Lamperti C, Tallaksen CM, Duffey P, Miller J, Whittaker RG, Baker MR, Jackson MJ, Clarke MP, Dhillon B, Czermin B, Stewart JD, Hudson G, Reynier P, Bonneau D, Marques W, Lenaers G, McFarland R, Taylor RW, Turnbull DM, Votruba M, et al:: Multisystem neurological disease is common in patients with OPA1 mutations. Brain 2010, 133:771-786.

38. Williams PA, Morgan JE, Votruba M: Opa1 deficiency in a mouse model of dominant optic atrophy leads to retinal ganglion cell dendropathy. Brain 2010, 133:2942-2951.

39. Kjer P, Jensen OA, Klinken L: Histopathology of eye, optic nerve and brain in a case of dominant optic atrophy. Acta Ophthalmol (Copenh) 1983, 61:300-312.

40. Alavi MV, Bette S, Schimpf S, Schuettauf F, Schraermeyer U, Wehrl HF, Ruttiger L, Beck SC, Tonagel F, Pichler BJ, Knipper M, Peters T, Laufs J, Wissinger B: A splice site mutation in the murine Opa1 gene features pathology of autosomal dominant optic atrophy. Brain 2007, 130:1029-1042.

41. Ceranić B, Luxon LM: Progressive auditory neuropathy in patients with Leber's hereditary optic neuropathy. J Neurol Neurosurg Psychiatr 2004, 75:626-630

42. Meyer E, Michaelides M, Tee LJ, Robson AG, Rahman F, Pasha S, Luxon LM, Moore AT, Maher ER: Nonsense mutation in TMEM126A causing autosomal recessive optic atrophy and auditory neuropathy. Mol Vis 2010, 16:650-664.

43. Rance G, Fava R, Baldock H, Chong A, Barker E, Corben L, Delatycki MB: Speech perception ability in individuals with Friedreich ataxia. Brain 2008, 131:2002-2012.

44. Li K, Singh A, Crooks DR, Dai X, Cong Z, Pan L, Ha D, Rouault TA: Expression of human frataxin is regulated by transcription factors SRF and TFAP2. PLOS ONE 2010, 5:e12286
45. Bahmad F, Merchant SN, Nadol JB, Tranebjaerg L: Otopathology in MohrTranebjaerg syndrome. Laryngoscope 2007, 117:1202-1208.

46. Wang QJ, Li QZ, Rao SQ, Lee K, Huang XS, Yang WY, Zhai SQ, Guo WW, Guo YF, Yu N, Zhao YL, Yuan H, Guan J, Leal SM, Han DY, Shen Y: AUNX1, a novel locus responsible for $\mathrm{X}$ linked recessive auditory and peripheral neuropathy, maps to Xq23-27.3. J Med Genet 2006, 43:e33.

47. Genís D, Dávalos A, Molins A, Ferrer I: Wolfram syndrome: a neuropathological study. Acta Neuropathol 1997, 93:426-429.

48. Singer JH, Glowatzki E, Moser T, Strowbridge BW, Bhandawat V, Sampath AP. Functional properties of synaptic transmission in primary sense organs. J Neurosci 2009, 29:12802-12806.

49. Brandt A, Khimich D, Moser T: Few CaV1.3 channels regulate the exocytosis of a synaptic vesicle at the hair cell ribbon synapse. J Neurosci 2005, 25:11577-11585

50. Glowatzki E, Fuchs PA: Transmitter release at the hair cell ribbon synapse. Nat Neurosci 2002, 5:147-154.

51. Pangrsic T, Lasarow L, Reuter K, Takago H, Schwander M, Riedel D, Frank T, Tarantino LM, Bailey JS, Strenzke N, Brose N, Müller U, Reisinger E, Moser T: Hearing requires otoferlin-dependent efficient replenishment of synaptic vesicles in hair cells. Nat Neurosci 2010, 13:869-876.

52. Santarelli R, Del Castillo I, Rodríguez-Ballesteros M, Scimemi P, Cama E, Arslan E, Starr A: Abnormal cochlear potentials from deaf patients with mutations in the otoferlin gene. J Assoc Res Otolaryngol 2009, 10:545-556.

53. Singer $\mathrm{JH}$, Diamond JS: Vesicle depletion and synaptic depression at a mammalian ribbon synapse. J Neurophysiol 2006, 95:3191-3198.

54. Hossain WA, Antic SD, Yang Y, Rasband MN, Morest DK: Where is the spike generator of the cochlear nerve? Voltage-gated sodium channels in the mouse cochlea. J Neurosci 2005, 25:6857-6868.

55. Pawson C, Eaton BA, Davis GW: Formin-dependent synaptic growth: evidence that Dlar signals via Diaphanous to modulate synaptic actin and dynamic pioneer microtubules. J Neurosci 2008, 28:11111-11123.

56. Santarelli R, Starr A, Michalewski HJ, Arslan E: Neural and receptor cochlear potentials obtained by transtympanic electrocochleography in auditory neuropathy. Clin Neurophysio/ 2008, 119:1028-1041.

57. Miyamoto RT, Kirk Kl, Renshaw J, Hussain D: Cochlear implantation in auditory neuropathy. Laryngoscope 1999, 109:181-185.

58. Brookes JT, Kanis AB, Tan LY, Tranebjaerg L, Vore A, Smith RJH: Cochlear implantation in deafness-dystonia-optic neuronopathy (DDON) syndrome. Int J Pediatr Otorhinolaryngol 2008, 72:121-126.

59. Rance G, Corben LA, Du Bourg E, King A, Delatycki MB: Successful treatment of auditory perceptual disorder in individuals with Friedreich ataxia. Neuroscience 2010, 171:552-555.

doi:10.1186/gm212

Cite this article as: Santarelli R: Information from cochlear potentials and genetic mutations helps localize the lesion site in auditory neuropathy. Genome Medicine 2010, 2:91. 